\title{
Intragastric foreign body: a rare cause of abdominal pain
}

\author{
J. Egea-Valenzuela ${ }^{1}$, F. Alberca-de-las-Parras ${ }^{1}$, F. J. Ruiz-López ${ }^{2}$, A. Martínez-Caselles ${ }^{1}$, J. Molina-Martínez ${ }^{1}$ \\ and F. Carballo-Álvarez ${ }^{1}$
}

${ }^{I}$ Services of Digestive Diseases (Gastrointestinal Endoscopy Unit) and ${ }^{2}$ Neumology. University Hospital Virgen de la Arrixaca. Murcia, Spain

\section{CASE REPORT}

A 54 year-old woman was admitted to the Neumology Service in our Hospital due to hemoptysis. Fifteen years ago she was diagnosed peptic ulcer, and received medical treatment with good evolution. During the present episode she suddenly suffered acute epigastric pain, not irradiated, not accompanied by nausea or vomiting and her injury worsened after food ingestion. Complete laboratory tests were carried out, with no abnormalities. Simple abdominal X-ray was anodyne, and ultrasound was informed as normal.

We were commented this case and, considering the patient's precedents, the decision was to run an upper endoscopy, which took place about 36 hours after the beginning of her symptoms. We could observe the presence of a thin long foreign body, penetrating gastric mucosa at both ends, located on prepyloric area (Fig. 1). It seemed to be a bone and mucosa presented incipient inflammatory reaction at impactation points. The foreign body was removed and we could see two small not complicated ulcerations (Fig. 2). The bone was a little chicken rib, about three centimeters long and had very sharpened ends.

After these findings, a second look was made on the abdominal X-ray. A more exhaustive study showed the presence of a small, long calcic image, about three centimeters long, located on upper right abdomen, which had not been detected in the first exams and seemed to be the chicken bone (Fig. 3). In the following hours the patient presented a good evolution, with no pain and normal oral feeding.

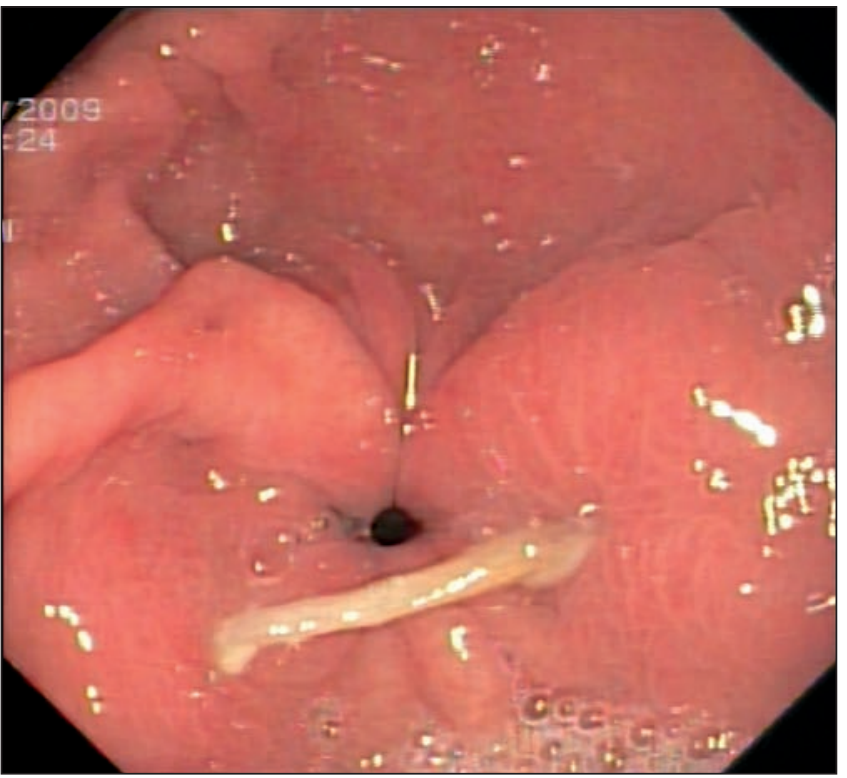

Fig. 1. Foreign body penetrating prepyloric mucosa.

\section{DISCUSSION}

Ingestion of foreign bodies is relatively frequent, especially in pediatric population and psychiatric patients. In healthy adults accidental ingestion is not rare, but foreign bodies usually pass spontaneously through the gastrointestinal tract and only a few need endoscopic procedures. About $10 \%$ of these patients suffer penetration of the foreign body and present some symptoms, so that an endoscopy is run for diagnosis or treatment. Only $1 \%$ suffers perforation of gastrointestinal wall, especially at esophagus or cecum, and present related complications such as wall abscesses, hemorrhage, peritonitis or intraabdominal abscesses, just to mention some of those described in literature. Radiology can be useful for diagnosis, especially in cases of great clinical suspicion or big sized foreign bodies or with metallic or calcic densities. Endoscopic renoval is safe when we face non complicated penetrations and endoclips may be used to close mucosal defects, definitively or as a previous procedure before surgery. 


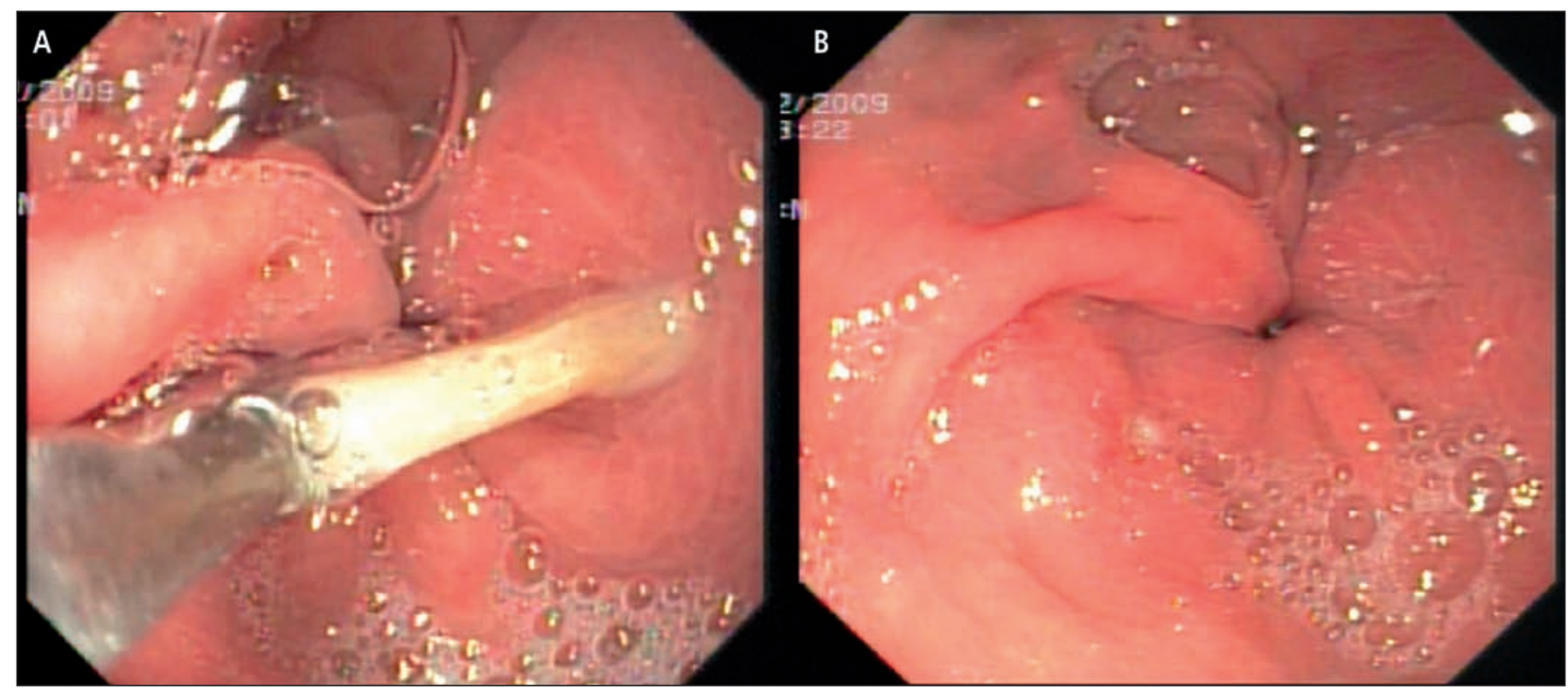

Fig. 2. A. Removal of the foreign body. B. We can see two small ulcers on the mucosa.

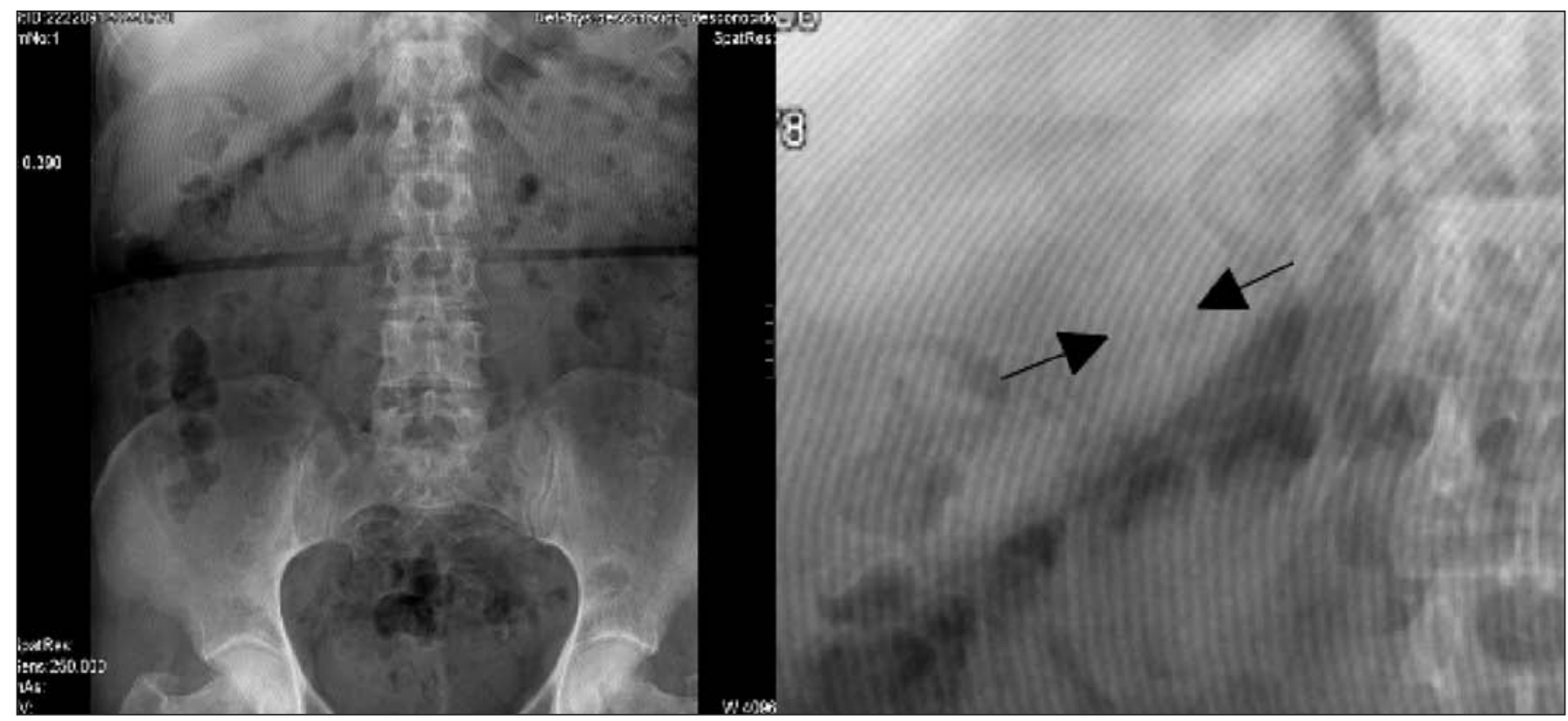

Fig. 3. X-ray in which the foreign body can be seen on the right upper quadrant. It was detected on the first study.

Impactation of an intragastric foreign body is an exceptional cause of abdominal pain, with not much reported cases. Moreover, most of these diagnoses were obtained after several radiological studies or after a laparotomy. This etiology should be considered in diagnosis of abdominal pain, especially in patients with atypical symptoms, acute sharp beginning of the symptoms or normality of the most frequent complementary studies. 


\section{RECOMMENDED REFERENCES}

1. Vivas Balcones D, Martínez Prada C, Torres-Gárate R, Sanz M, Antolín Arias J, Cigüenza Gabriel R. Dolor abdominal de etiología muy infrecuente. Rev Clin Esp 2006; 206(11): 583-4.

2. Jin-Soo K, Hyung-Keun K, Young-Seok C, Hiun-Suk C, Chang-Whan K, Byung-Wook K, et al. Extraction and clipping repair of a chicken bone penetrating the gastric wall. World J Gastroenterol 2008; 14(12): 1955-7.

3. Eisen GM, Baron TH, Dominitz JA, Faigel DO, Goldstein JL, Johanson JF, et al. Guideline for the management of ingested foreign bodies. Gastrointest Endosc 2002; 55: 802-6.

4. Mehran A, Podkameni D, Rosenthal A, Szomstein S. Gastric perforation secondary to ingestion of sharp foreign body. JSLS (2005)9: 91-3. 